Www.jmscr.igmpublication.org

Index Copernicus Value: 79.54

ISSN (e)-2347-176x ISSN (p) 2455-0450

crossref DOI: https://dx.doi.org/10.18535/jmscr/v7i5.05

\title{
Study of Etiological and Clinical Profile of Hepatomegaly in Children up to 10 years of Age
}

Authors

\author{
Dr Sasmita Devi Agrawal ${ }^{1}$, Dr Himanshu Sekhar Sahoo*, Dr Sri Harsha Lanke, \\ Dr Sidhant Swarup, Dr Gautam Tripathy, Dr Rajendra Meher \\ ${ }^{1}$ Department of Paediatrics, Hi-Tech Medical College, Bhubaneswar, India \\ *Corresponding Author \\ Dr Himanshu Sekhar Sahoo \\ Email: himanshu000sahoo@gmail.com, Mobile number- 8280204000 (India)
}

\begin{abstract}
Background: Liver enlargement could be an indicator of underlying liver disease, even if there are usually no symptoms associated with it. On the other hand, Symptoms of a grossly enlarged liver include abdominal discomfort or feeling full could potentially provide an insight into an underlying serious pathology It could be due to a various number of infective/Inflammatory, Congestive, infiltrative, proliferative (Kupfer cell) reasons. It could also be a manifestation of an underlying intrinsic hepatic disorder and Storage related disorders.

Material and Methods: All children upto the age of one month to 10 years presenting to Hitech Medical College and Hospital with increase in liver span were included in the study over the span of the past year. Patients were subjected to routine investigations and in some cases some special investigations depending on provisional diagnosis after detailed history and physical examination.

Results and Conclusion: The most common age group presenting with hepatomegaly was found to be between 1 to 5 years followed by 5 to 10 years. The most common aetiology was found to be infections and the most common presenting signs and symptoms were found to be fever, anemia followed by oedema and jaundice.
\end{abstract}

Keywords: Hepatomegaly, infections, fever, aetiology.

\section{Introduction}

Hepatomegaly is an enlargement of the liver resulting from an increase in the number or size of cells and structures within the liver. In normal children, the liver edge may be palpable up to 2 $\mathrm{cm}$ below the right costal margin at the midclavicular line. Clinical estimation of the liver span has a much stronger correlation with hepatomegaly than the liver projection below the costal margin does as a single indicator of liver size. It is the distance between the upper and lower margins of the liver at the right midclavicular line. The upper margin should be determined by percussion and the lower margin by either percussion or palpation. Liver span has a curvilinear relation to age, height, weight, and body surface area. ${ }^{(1-4) .}$ A normal liver span ranges from $5.9 \mathrm{~cm}( \pm 0.8 \mathrm{~cm})$ in the first week of life to 6.5 to $8 \mathrm{~cm}$ by 15 years of age.

Radiographic assessment, clinical examination. Ultrasonography, computed tomography (CT), magnetic resonance imaging (MRI) are all 
established as reliable measures for estimation of into a number of underlying disorders Table 1. liver size. Hepatomegaly could provide insight

Table.1 The various underlying pathologies behind Hepatomegaly

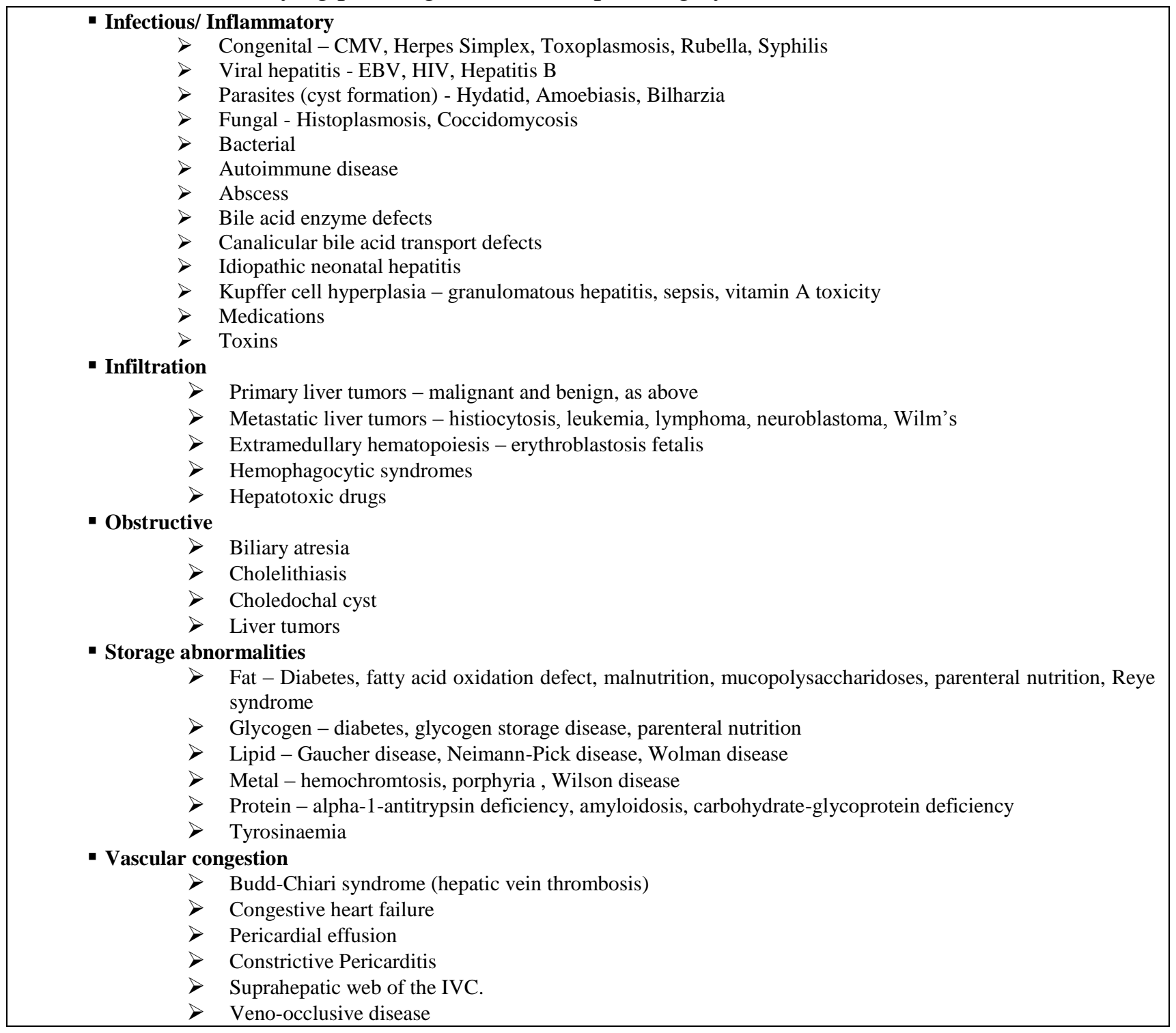

\section{Materials and Methods}

This was a hospital based observational study which included all children from the age of one month to 10 years presenting to Hi-Tech Medical College and Hospital with increase in liver span were included in the study over the span of the past year. After thorough examination and evaluation, hepatomegaly was defined using the increased liver span as measurement in relation to the expected span for age. In infants the expected values were taken as $5-6 \mathrm{cms}, \quad 6-8 \mathrm{cms}$ in the rest of the children upto 5 years and upto $9 \mathrm{cms}$ in children between 5-10 years.
Upper border of liver is marked by percussion in the right mid-clavicular line. The lower border is marked by both percussion and palpation from right iliac fossa to the right hypochondrium. The distance between the upper marking and lower marking in the right mid-clavicular line is measured with calibrated tape. This measurement gives the span of the liver. Umbilicus was taken as an anatomical landmark and the hepatomegaly was graded into Mild (Liver enlarged, but not reaching up to umbilicus), Moderate (Hepatomegaly reaching upto umbilicus) and severe (crossing the level of umbilicus). 
Investigations ranging from Complete Blood Counts, urine and stool examinations, Liver Function Tests and X-ray and depending on the provisional Diagnosis and necessity Monteux, widal test, blood culture \& sensitivity, tridot, dengue serology, QBC, coagulation studies, USG, bone marrow examination, lymph node and liver biopsy were done.

\section{Inclusion Criteria}

- Children more than 1 month of age but less than 10 years of age who were admitted with hepatomegaly are included in the study.

\section{Exclusion Criteria}

- Infants less than 1 month of age and Children more than 10 years of age
A proper informed and written consent was obtained from all the concerned authorities.

Statistical Analysis was done using IBM SPSS software. Pearson's chi-squared test was used to determine the significant difference between the expected frequencies and the observed frequencies in both groups. $\mathrm{P}$ values $<0.01$ were taken as significant findings.

\section{Results and Observations}

The Mean age group of the study population was 4.82 ( \pm ) 2.893. Majority of the cases $83(56.8 \%)$ presenting with hepatomegaly were between 1-5 years. $57(39 \%)$ of them were between 5-10 years. Only $6(4.1 \%)$ were below the age of one year. Table 2.

Table 2 Age distribution of the study population

\begin{tabular}{|l|c|c|c|c|c|c|}
\hline AGE & \multicolumn{3}{|c|}{ NUMBER OF CHILDREN } & \multicolumn{2}{c|}{ (n=146) } \\
\hline & Male & \% & Female & \% & Total & \% \\
\hline L1 YEAR & 14 & 9.59 & 6 & 4.11 & 20 & 13.7 \\
\hline 1-5 YEARS & 32 & 21.92 & 37 & 25.34 & 69 & 47.26 \\
\hline 5-10 YEARS & 36 & 24.66 & 21 & 14.38 & 57 & 39.04 \\
\hline TOTAL & 82 & 56.16 & 64 & 43.84 & 146 & 100 \\
\hline
\end{tabular}

Sex distribution of the study population was found $\quad$ presented with mild hepatomegaly while 56 to have a slightly male predominance with 82 $(56.16 \%)$ of the children being male and $(38.36 \%)$ and $13(8.9 \%)$ children presented with 64(43.84\%) females. $77(52.74 \%)$ children moderate and severe hepatomegaly. Chart 1.

Chart 1 Degree of hepatomegaly in the study population in respective age groups

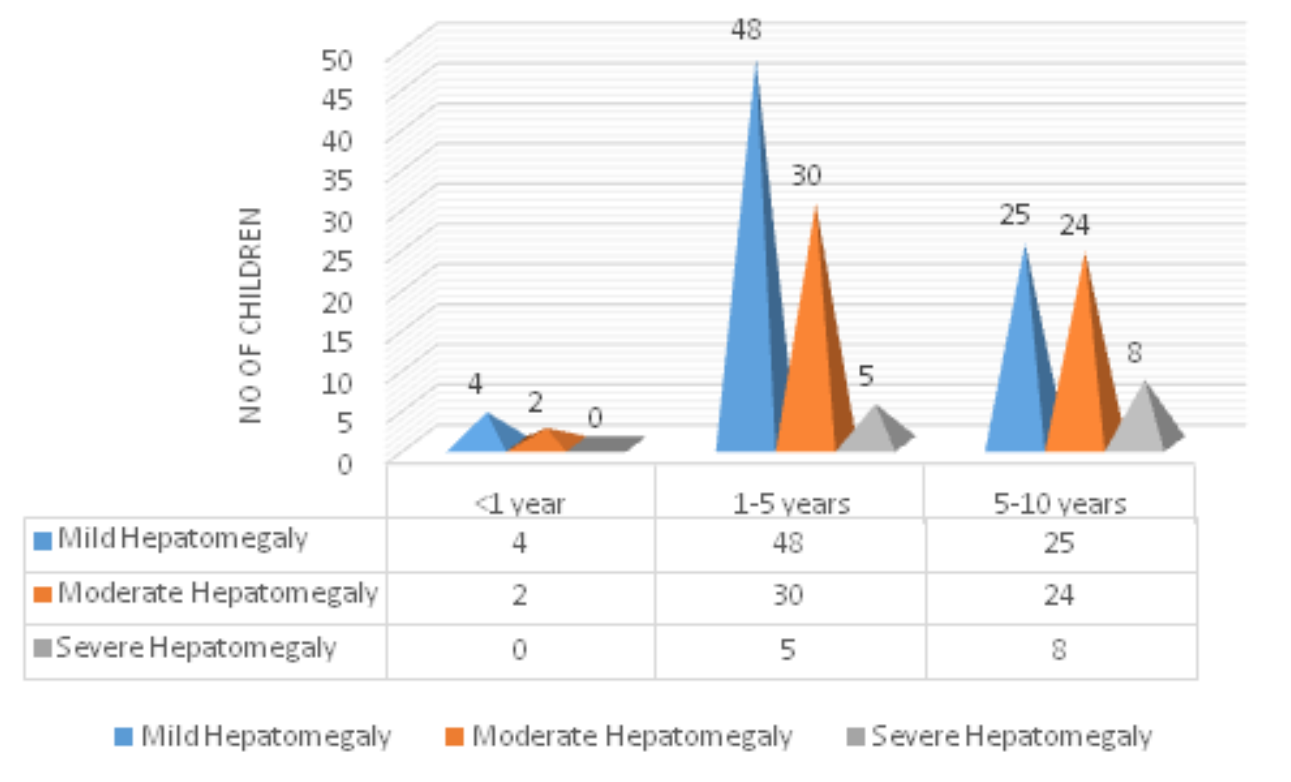


Accompanying splenomegaly was found in $95(65.1 \%)$ of the children presenting with hepatomegaly. $77(52.7 \%)$ children presented with mild hepatomegaly. 56(38.4\%) children had moderate hepatomegaly and $13(8.9 \%)$ had severe hepatomegaly respectively.

A variety of signs and symptoms have been observed in the study population. Table 3 .

Table 3 Associated Signs and Symptoms

\begin{tabular}{|lc|c|}
\hline Associated Signs and Symptoms & Frequency $(\mathbf{n = 1 4 6})$ & Percent \\
\hline Fever & 125 & 85.62 \\
\hline Splenomegaly & 95 & $65.07 \%$ \\
\hline Jaundice & 42 & 28.77 \\
\hline Edema & 45 & 30.82 \\
\hline Bleeding & 27 & 18.49 \\
\hline Lymph Node enlargement & 26 & 17.81 \\
\hline Anaemia & 102 & 69.86 \\
\hline Ascites & 8 & 5.48 \\
\hline Developmental delay/ & 8 & 5.48 \\
Neurological deterioration & & \\
\hline Dysmorphic features & 19 & 13.01 \\
\hline Haemangiomas & 5 & 3.42 \\
\hline Other & 11 & 7.53 \\
\hline
\end{tabular}

125 children presented to the hospital with Fever as chief complaint and was found to be the most common presentation $85 \%$ in the study population.102 (69.86) children presented with anemia. Associated Splenomegaly was found in 95 children $(65.07 \%)$. Jaundice was found in 42 children. (28.77\%)

Some of the other Signs and symptoms observed in the study population were Convulsions, eye related problems especially cataracts. Dysmorphic features like microcephaly were noted in 11 children.
Other associated problems alongside hepatomegaly were such as respiratory problems like infections, Malnutrition (categorized as storage disorder related causes), diabetes and hypertension.

Most number of cases were noted in the study population of 4 and 5 years. $29 \%$ of the male population below 1 year of age suffered from infectious causes of hepatomegaly while vascular congestion related causes affected the majority $21 \%$ of the female population below the same age. Table 4.

Table 4 Age Distribution and Diagnosis

\begin{tabular}{|l|c|c|c|c|c|c|}
\hline \multirow{2}{*}{ Age } & \multicolumn{2}{|c|}{$<\mathbf{1}$ year } & \multicolumn{2}{c|}{$\mathbf{1 - 5}$ years } & \multicolumn{2}{c|}{$\mathbf{5 - 1 0}$ years } \\
\hline \multirow{2}{*}{ Sex } & $\mathrm{M}$ & $\mathrm{F}$ & $\mathrm{M}$ & $\mathrm{F}$ & $\mathrm{M}$ & $\mathrm{F}$ \\
& $\%$ & $\%$ & $\%$ & $\%$ & $\%$ & $\%$ \\
\hline Infectious/ Inflammatory & 29 & 10 & 33 & 19 & 40 & 24 \\
\hline Infiltration & 3 & 2 & 2 & - & - & 1 \\
\hline obstructive & 5 & 6 & 6 & 2 & 6 & 2 \\
\hline Storage disorders & 2 & 4 & 4 & 1 & - & 2 \\
\hline Vascular Congestion & 18 & 21 & 20 & 13 & 12 & 13 \\
\hline Total out of age group & 100 & 100 & 100 & 100 & 100 & 100 \\
\hline
\end{tabular}

$33 \%$ of the male population between 1-5 years suffered from infectious/inflammatory causes of hepatomegaly while the trend of vascular congestive related causes from the previous age group continued ( $20 \%$ females of $1-5$ years) 


\section{Discussion}

In the present study most cases of Hepatomegaly were found to be attributable to infectious and inflammatory causes such as viral hepatitis and other infections resulting in the most common presentation of fever and respiratory problems etc. $\mathrm{P}$ value was 0.0017 indicating that it was statistically significant. In this study $42 \%$ cases of mild hepatomegaly were due to infections, $27 \%$ due to passive congestion and others were hemolytic,neoplastic and miscellaneous causes attributed to kwashiorkor acute glomerulonephritis, type-I diabetes. As can be related to the reports by Ramchandran, Godfrey JJ $^{(5)}$ and E.R. Seddeshi ${ }^{(6)}$, K. Jagadish, A.R. Patwar, SK. Sarin ${ }^{(7)}$

Moderate hepatomegaly was seen in $25 \%$ cases, Out of which majority were infectious and vascular congestive causes and some due to cholestatic jaundice of infancy, one case of metabolic disorder and miscellaneous disorders.
Massive hepatomegaly was noted in cases of infiltrative/neoplastic (leukemia) and metabolic disorders. Hemoglobin level $<7$ gms was noted in 102 children and was the other commonest finding mainly attributable to iron deficiency anemia and malnutrition.Out of the children presenting with jaundice, unconjugated hyperbilirubinemia was significantly common. (Malaria, Thalassemia, sickle cell etc.) 45 children had generalized edema and ascites attributable to chronic hepatitis and cardiac reasons. Associated splenomegaly was mild (1-3 cms) in majority of the cases $61 \%$, moderate $(4-7 \mathrm{cms})$ in $33 \%$ and massive $(>7 \mathrm{cms})$ in $6 \%$ cases.Dr. Reddy Y.R. and Jayalaxmi ${ }^{(8)}$ in their study of splenomegaly in infants and children found that hepatomegaly was an associated finding in $96 \%$ cases of splenomegaly.

Champatiray J et al ${ }^{(9)}$ and Somaiah G et al. ${ }^{(10)}$ were previous studies that provided insight into the etiology of hepatomegaly in children. Chart 2

Chart 2: Findings of the present study in relation to previous studies

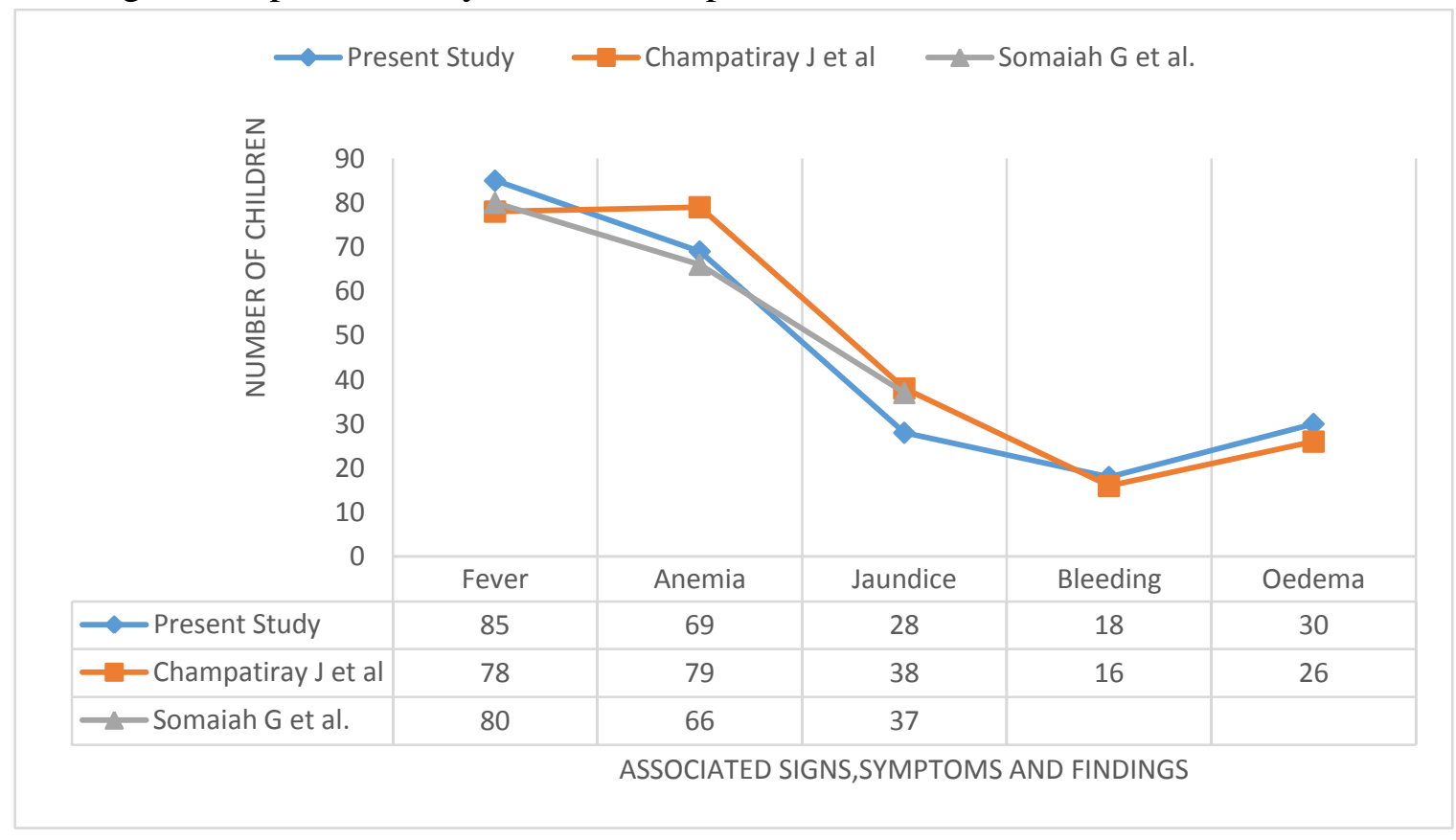

\section{Conclusion}

The isolated presentation of a child with hepatomegaly can be challenging and should not just be ruled out at first glance as it could be hiding a potentially serious problem underneath. Because of the wide range of etiologies and the variable outcome probabilities, each case should be diagnosed only after a careful history taking, physical examination and corresponding diagnostic modalities. As it can be established from the number of studies on the past alongside the present study the most probable signs, 
symptoms should be correlated to and the diagnostic modalities should be used in the corresponding order to reach a final diagnosis. Proper work up, guidance and follow up are to be given.

\section{References}

1. Wolf DC. Evaluation of the size, shape, and consistency of the liver. In: Clinical methods: The history, physical, and laboratory examinations, 3rd edition, Walker HK, Hall WD, Hurst JW (Eds), Butterworths, Boston 1990.

2. Naylor $C D$. The rational clinical examination. Physical examination of the liver. JAMA 1994; 271:1859.

3. Walker H, Hall W, Hurst J. The history, physical and laboratory examinations, 3rd, Butterworths, Boston 1990.

4. Kratzer W, Fritz V, Mason RA, et al. Factors affecting liver size: a sonographic survey of 2080 subjects. J Ultrasound Med 2003; 22:1155.

5. Ramachandram S. Godprey. J.J Typhoid hepatitis JAMA, 1974, 230, 236-240, Indian Paediatrics.

6. E.R. Siddeshi, et.al. Typhoid hepatitis, Indian paediatrics, 1989, 26, 512-523.

7. K. Jagadish, A.K. Patwari, S.K. Sarin, C. Prakash, D.K. Hepatic manifestations in typhoid fever - Indian Paediatrics, 31-77, p. 807-811, 1994.

8. Reddy Y.R. et.al. Hepatic lesion in childhood tuberculosis, Indian paediatrics, 1964, 2, 25-47.

9. Champatiray J, Panigrahi D, Mondal D, Satpathy SK. Study of aetiological profile, clinical presentation and outcome of hepatosplenomegaly in children between 1 month and 14 years of age. Int J Contemp Pediatr 2017;4:927-32.

10. Anusha G, Somaiah G, Siddique AM, Srikanth B. Study of Etiological and Clinical Profile of Hepatosplenomegaly in Children between 1 Month and 15 Years of Age. Scholars Journal of Applied Medical Sciences. 2014;2(2A):554-7 